\title{
Regularidade e Agressividade: Categorias de Análise no Recreio de um Aluno com Deficiência Mental
}

Cláudio Marques Mandarino*

\section{Resumo}

No artigo abordamos o tema referente à integração de um aluno com deficiência mental matriculado no ensino fundamental, tendo como espaço de análise as manifestações corporais desse sujeito. O seu objetivo está em observar as relações que o mesmo estabelece com os outros escolares. Na sua primeira parte tratamos da integração escolar e posteriormente estudos sobre o recreio. Num segundo momento, comentamos sobre o corte micro-etnográfico, utilizando a observação como técnica de coleta de informação. Foram identificadas e analisadas duas categorias: regularidade e agressividade. Na conclusão é destacado que existem condições adversas para este aluno no recreio. Destacamos, também, que deve haver um maior comprometimento por parte da escola para garantir a implementação da proposta de integração.

Descritores: Recreio; Integração; Deficiência Mental

\section{Abstract}

This article discusses the integration of a mentally disabled student enrolled in an elementary school, based upon the analysis of his body behavior. The goal is observing the relationships he establishes with other students. In the first part, we discuss school integration, then approaching the recess time. In the second part, we make some comments on the microethnographic cut, using observation as a data collection technique. Two categories were identified and analyzed: regularity and aggressiveness. The conclusion outstands the existing adverse conditions for this student during the recess time. We also highlight that the school management must increase its commitment in order to assure the integration proposal implementation.

Key words: Recess time; Integration; MentalDisability

\section{Introdução}

A escola tal como a conhecemos, com salas de aulas, divisões por séries, por idades, avaliações, disciplinarizaçâo dos corpos, etc, é o entrecruzamento de várias práticas em que estiveram presentes o movimento iluminista, um novo conceito de infância, a influência dos protestantes e uma nova forma de controle, ou seja, o autocontrole ${ }^{1}$.

A participação de um aluno com deficiência mental dentro da escola tem, atrás de si, uma legitimação de novos olhares que vão somando-se aos discursos presentes anteriormente. Neste sentido, a realização de um estudo com um aluno com deficiência mental matriculado numa escola municipal do ensino fundamental deve-se a toda uma trajetória que envolveu as lutas para democratizar o espaço escolar. Uma delas se refere à integração. E importante pontuar que ela nos aproxima de um debate contemporâneo e está ancorada em regimes de verdade que a legitimam..

Neste estudo trataremos da integração, no recreio, de um aluno com deficiência mental matriculado numa escola do ensino fundamental. Num espaço que possui esse cotidiano parece-nos importante refletir sobre este momento escolar. Dessa forma nos perguntamos: Como este aluno se manifesta corporalmente no recreio? Que tipo de situações ele vivência? Que relações ele estabe- 
lece com os outros escolares? Que lugar ele ocupa no recreio?

Esses questionamentos nos levaram a formular o seguinte problema:

\section{Como as relações que envolvem poder no recreio influenciam as manifestações corporais de um aluno com deficiência mental na escola do ensi- no fundamental?}

Definimos relações de poder como uma força e uma ação sobre a ação, sobre as ações eventuais ou atuais, futuras ou presentes, é o conjunto de ações sobre ações possíveis. (Foucault, apud Deleuze, 1998)

Por manifestações corporais entendemos que são toda e qualquer manifestação que um sujeito faz e que possui uma intencionalidade de sua parte. Ela pertence a uma rede de relações que se estabelecem no cotidiano escolar.

Para seguirmos adiante na nossa proposta, fizemos uma revisão de literatura que nos aproximou de duas perspectivas de análise: na primeira temos a escola, portanto, pareceu-nos oportuno tratar da integração educacional, pois ela possibilita a presença do aluno com deficiência mental na escola do ensino fundamental; na segunda, buscamos em estudos que trataram sobre o recreio outros olhares que valorizam este momento escolar.

As situações que ocorrem no recreio irão ocupar um espaço de valor ou de desvalor, segundo a importância que a escola dá a esse momento. Sendo assim, pretendemos apresentar alguns olhares sobre o recreio, mapeando-o com base em considerações referentes a autores que refletiram sobre ele. O objetivo, portanto, será o de observar como o aluno com deficiência mental estabelece relações com os outros escolares. Como podemos perceber, todas essas análises, são feitas tendo como entendimento a existência da própria escola, o local onde estaremos presentes.

\section{A Instituição Escolar e a Integração}

O princípio da integração na educação especial situa a escola como um espaço plural, oferece-nos outro local para que as manifestações corporais de um aluno com deficiência mental possam ser estudadas.

Neste estudo, adotaremos o vocábulo integração e não inclusão (mais utilizado atualmente) porque temos a compreensão de que ambos são enunciados que só se legitimam num quadro de conhecimento que lhes confira sentido. Dessa forma, elas são, também, categorias de análises. A escolha do primeiro se refere a uma decisão de cunho optativo, pois, entendemos que elas podem conduzir a uma visão um tanto quanto idealista de sociedade. O que não afasta a idéia de que elas devam ser procuradas. Uma compreensão de que elas resultam num funcionamento harmonioso entre as pessoas, traduz uma ingenuidade sobre a sua concretização. Podemos entendê-las, portanto, como uma das possibilidades de se propor políticas públicas às pessoas com "deficiência".

Na legislação brasileira, foi a partir de 1961 que a integração começou a figurar nos textos políticos, como, por exemplo, a Lei $\mathrm{n}^{\circ} 4.024$, que tratava das Diretrizes e Bases da Educação Nacional, reafirmando o direito dos "excepcionais" à educação, indicando, no seu art. 88, que, para integrá-los à comunidade, sua educação deverá, dentro do possível, enquadrar-se no sistema geral deeducação(MAZZOTTA, 1996).

O processo por que passou a integração após todos esses anos, em termos de normas, pode ser sintetizado no capítulo que trata da Educação Especial da nova Lei de Diretrizes e Bases da Educação Nacional, Lei n ${ }^{\circ} 9.394$, de 20-12-1996, em que o art. 58 aparece da seguinte forma:

\footnotetext{
'Entende-se por educação especial, para efeito desta lei, a modalidade de educação escolar, oferecida preferencialmente na rede regular de ensino, para educandos portadores de necessidades especiais".
}

No parágrafo único do art. 60, a lei é bem clara em relação às prioridades de atendimento:

\footnotetext{
"O poder público adotará, como atendimento preferencial, a ampliação do atendimento aos educandos com necessidades especiais na própria rede pública regular de ensino, independentemente do apoio às instituições previstas neste artigo".
} 
Resgatando o Decreto 3.298 de20-12/1999 que regulamenta a Lei 7.853 que dispõe sobre a Política Nacional para a Integração da Pessoa "Portadora" de Deficiência, quando trata do acesso à educação, em seu artigo 24 destaca a seguinte medida:

\footnotetext{
"A matricula compulsória em cursos regulares de estabelecimentos públicos e particulares da pessoa portadora de deficiência capazes de se integrar na rede regular de ensino". (Conselho Regional de Serviço Social, 2000,p.205)
}

Essas leis tiveram efeitos diretos sobre as políticas públicas na área da Educação Especial, fazendo com que Municípios e Estados se mobilizassem para garantir esse princípio. Como uma breve análise sobre a repercussão dessa lei, destacamos que a integração é um processo que deve ser tratado de forma política, ética e teórica.

Política, porque está garantido por lei na Constituição de 1998, constando na nova Lei de Diretrizes e Bases da Educação Nacional. Dessa forma, sua concretização dentro da escola passa por uma relação de poder que inclui ou exclui. A decisão política de aceitar um aluno com deficiência mental está relacionada a uma ação que passa pela própria escola. A presença de um aluno "especial" dificilmente passa despercebida dentro da instituição.

Ética, porque a integração pode ser compreendida como uma possibilidade de inserção na sociedade, mesmo entendendo que é uma "conquista parcial e provisória, pois não é nem garantida pela existência de boas intenções, nem tampouco deve ser impedida pela existência de sérias diferenças" (BURBULES e RICE, 1993).

Fazemos esse destaque porque não somos defensores de idéias fechadas ou de verdades únicas e acreditamos que a integração abre a possibilidade aos pais ou responsáveis pelo aluno com deficiência mental, possuírem outras escolhas para a sua escolarização.

Teórica, porque tem sido seguidamente objeto de estudo nos meios acadêmicos. E por intermédio de diversos pesquisadores dessa área que os regimes de verdade a favor ou contra a integração têm estabelecido uma relação de poder em que os discursos, versos, não somos muitas vezes, se defensores de idéias chocam.

$\mathrm{Na}$ discussão sobre a integração, podemos acreditamos que a dizer que a integração abre a Declaração depossibilidade aos $\mathrm{S}$ a $1 \mathrm{a} \mathrm{m}$ a $\mathrm{n}$ a pais ou (CORDE, 1994) foi responsáveis pelo um dos grandes aluno com impulsionadores desse modelo. Ela se deficiência mental, caracteriza basi-possuírem outras camente pela sua escolhas para a sua contemporaneidade escolarização. sobre as necessida-

des educacionais especiais. $\mathrm{O}$ seu objetivo maior pauta-se na educação para todos e no princípio de integração, estimulando os estudos sobre essa questão e destacando que eles são fundamentais para que se possa tratar com mais propriedade desse processo.

Dentro de uma proposta alternativa para os novos rumos da educação especial, a Declaração de Salamanca (CORDE, 1994) constitui-se em um documento quevislumbra, por meio da integração educacional, um projeto que envolve todos os indivíduos da sociedade.

Nas discussões educacionais atuais, os estudos sobre a escola têm indicado que ela é um espaço valorizado pela pluralidade dos sujeitos ali presentes. Isso a caracteriza como um espaço de múltiplas opiniões, gestos, ritmos, ações, etc, revelando que se devem respeitar as individualidades e que toda e qualquer forma de legitimação de um modelo a ser seguido não passa de uma posição muito particular na qual as diferenças entre as pessoas aparecem em categorias hierárquicas ou, como destaca SKLIAR (1999), acabam constituindo uma alteridade deficiente $^{2}$.

Na integração de alunos com deficiência mental no ensino fundamental, é necessário ter-se em conta que "não existe nenhum princípio consensual dizendo que tal realização nãoépossível" (BURBULES e RICE, 1993). 
Nesse sentido, é de perceber-se que ações que incluam essas populações tendem a ser mais positivas do que o contrário.

Para nós, a proposta da integração representa uma lógica diferente daquela que foi dada para a constituição da escola na sociedade moderna. Entendemos, porém, que ela coloca um peso muito grande na concretização, pois, o que realmente significa estar integrado ou incluído?

Tomamos como exemplo a questão do preconceito racial, pois um branco e um negro podem ser colegas de sala de aula durante todo um período de escolarização, e o preconceito do primeiro em relação ao segundo não é eliminado. A integração é um enunciado ${ }^{3}$ que somente existe porque se constituiu dentro de um quadro argumentativo, legal e ético.

Em nosso entendimento, essa é uma possibilidade para que estes sujeitos possam exercer a sua cidadania, garantindo a sua presença na escola. Dessa forma, diminuir-se-ao as expectativas que a integração traz. A escola do ensino fundamental, nesse contexto, é o local onde essa concretização se dará. Sobre ela recai toda uma verdade para identificar se essa política está, ou não, se concretizando.

Uma contribuição importante sobre este tipo de análise, em relação aos regimes de verdade, é feita por GORE (1994, p. 10-1) explicando que são construídas as "suas próprias versões de verdade, suas próprias versões daquilo que conta, de quem está autorizado a falar, para constituir os regimes de verdade", e o contexto onde fazemos estes registros possui uma riqueza de análises.

Certamente a educação especial enuncia sobre o deficiente mental uma verdade visível aos olhos de quem compõem a sua instituição. O que interessa, agora, é identificar os saberes que a escola fundamental constitui em relação aos alunos com deficiência mental.

Se, na escola especial, esse sujeito é desnudado e reabsorvido pelos enunciados que se fazem dele e que o sustentam, presente agora na escola do ensino fundamental, novos olhares são feitos. Até bem pouco tempo, a escola especial era o único lugar onde se produ- zia uma verdade sobre esse sujeito. Agora, outra representação é conferida a ele, como, por exemplo, o de que não precisa ficar enclausurado num local específico. O delineamento da proposta da integração está em investir sobre a convivência também, dos deficientes mentais, no espaço escolar.

A escola oportuniza diversas experiências aos seus escolares. Nelas estão presentes o ensino, a aprendizagem, a estrutura disciplinar, o conhecimento, o reconhecimento das diferenças, etc. Nessa forma de relação estabelecida para o corpo dos escolares, isto é, ficar sentado durante quatro horas na sala de aula, é reservado um espaço de tempo que varia entre 10,15 e/ ou 20 minutos: o recreio escolar.

A característica presente na sala de aula valoriza um aspecto específico do educando: o intelectual. No recreio, porém, existem outras aprendizagens que geralmente não estão nas grades curriculares, mas estão presentes na formação dos alunos e das alunas. Esse momento, portanto, será o palco de outras vivências que agirão sobre os corpos dos escolares. Dessa forma deslocamos nosso olhar para este momento escolar.

\section{Olhares sobre o Recreio Escolar}

A tradição da Educação Física em estudos que tratam sobre o recreio escolar é pequena e recente. Alguns dos estudos pesquisados para tratar desse momento escolar deslocaram seu olhar para o brincar, para o gênero, para formas de agressividade e para o desporto.

$\mathrm{O}$ recreio faz parte de um momento institucional em que os escolares utilizam o tempo e o espaço sem o controle do adulto. Isso parece ser uma definição inicial, visto que as suas variações somente ocorrerão quando for necessário organizá-lo, pois não é um local livre das coerções.

Falar sobre o recreio escolar significa aproximar-se do que os estudantes podem aprender, das comunicações e das ações explícitas que são legitimadas e aprovadas. Dessa forma, estamos tratando do currículo, das regras e dos procedimentos pelos quais as oportunidades são proporcionadas a cada um durante as interações. 
Com essa compreensão, aproximamo-nos do entendimento de CHERRYHOLMES (1993,p. I45),quando co-menta sobre o currículo dizendo que este "pode ser entendido como o estudo daquilo que é valorizado e priorizado, assim como daquilo que é desvalorizado e excluído".

Quando escreveu sobre o recreio como um espaço desportivo, SANTOS (1998, p. 111) iniciou seu texto dizendo que "depois de passar algumas horas envolvidas com aquilo que é tido como a parte séria da escola, as crianças estão prontas para o recreio". Mais adiante comentou que:

\footnotetext{
"Se ficarmos um pouco mais atentos e observarmos o que acontece naquele ambiente caótico, iremos perceber algumas regularidades que quebram, em parte, com esta primeira compreensão", (idem.)
}

Resgatamos essas compreensões porque, quando se começa a tratar desse momento escolar, é importante tentar mapear as reflexões que contribuirão para a presente análise.

Entendemos que, no recreio, as práticas de violência, relações de gênero, sociais e econômicas podem ser identificadas como elementos que estabelecem relações de poder e constituem certas manifestações corporais, das quais os escolares não estão desvinculados.

Dessa forma, a partir dos pressupostos da ecologia do desenvolvimento, RAMALHO (1996) referiu-se ao recreio, destacando que ele é o espaço que as crianças utilizam para ações de jogar sozinhas ou com a participação de outras, sendo, então, um terreno de atividades vivenciadas pelas crianças na rotina pré-escolar.

FARIA (1999) desenvolveu um estudo valorizando o tempo e o espaço escolar e comentou que o pátio não é somente um local de controle de ação dos outros ${ }^{4}$, mas também onde se realizam rituais e práticas na construção implícita e explícita de valores e conhecimentos. Mais adiante comentou que:

"E nos pátios que as crianças utilizam o seu tempo para escolher, criar e realizar práticas corporais diversas. Práticas essas que dizem respeito aos seus desejos, prazer e necessidade de movimentar-se na escola", (p.305)
Essa reflexão foi feita pelo autor para explicar que o recreio possibilita uma outra forma de rotina na escola, diferente das normas que esta estabelece para o convívio dos escolares. Por outro lado, ALMEIDA (1999), ao valorizar os aspectos interativos, comenta que ninguém desconhece o que ocorre nos pátios escolares nos momentos que antecedem o sinal para a entrada em sala de aula.

\footnotetext{
"Aparentemente se configura uma grande confusão, uma bagunça generalizada em que há uma participação majoritária dos alunos. Se observarmos atentamente, veremos animados papos, brincadeiras de pique, leitura, troca de figurinhas, futebol de bola de papel (bola de meia, chapinha, garrafa, e outros), prática de jogos populares, etc."(p.311)
}

Quanto à planificação do espaço de recreio nas escolas, as crianças (8-12 anos) preferem, por ordem de importância, os espaços desportivos (1), as zonas de jogo livre (2), as zonas verdes - nicho ecológico (3), os espaços de aventura (4), e as áreas de descanso (5) (PEREIRA, NETO eSMITH, 1997). Paraesses autores, os recreios são os espaços escolares em que ocorrem mais comumente os comportamentos de violência - particularmente nos espaços exteriores.

Dessa forma, pode-se entender que as situações dos recreios e dos jogos nas escolas também apresentam uma realidade preocupante, a qualidade do espaço e dos equipamentos é pobre e pouco considerada no seu impacto sobre as atividades de jogo livre nos intervalos do tempo escolar (NETO, 1997). Nos estudos sobre a violência no espaço escolar, esse autor comenta que a maior parte dos comportamentos anti-sociais ocorrem nos recreios (56\%), seguido dos corredores e escadas (19\%), sala de aula (31\%) e outros locais (12\%).

Analisando-se por outro ângulo, percebe-se que os mais velhos tendem a dominar os espaços de recreio com práticas desportivas, como o futebol, que marginaliza geralmente as meninas e os rapazes mais novos. Os mais velhos, e com mais competência para a prática de futebol, têm o seu lugar na equipe e o campo reservado (PEREIRA,NETO e SMITH, 1997).ANumestudo realizado nas escolas inglesas, destacou-se o domínio masculino, no espaço físico duranre os recreios, por meio de 
práticas como o futebol, (GRUGEON,IN: ALTMANN, 1999). 0 mesmo fenômeno tambémfoi identificado por SANTOS (1998). Fazendo um viés com o que estamos resgatando, destacamos um estudo realizado num recreio de uma escola especial para deficientes mentais (MANDARINO e NETTO, 1999).Ali registramos que existe esta tendência de os meninos maiores, mais fortes, ocuparem os espaços desportivos. Mais adiante, comentou-se que aquele não era um espaço de liberdade, mas, sim, de dominação e segregação.

As relações de poder que se estabelecem no recreio constituem um quadro no qual as relações ali presentes incitam, seduzem, anulam, estimulam, oportunizam, disputam por meio da violência, das afinidades dos grupos e da cotidianidade. Dessa forma, pretendemos conhecer algumas de suas possibilidades de manifestações corporais, pois é no recreio que os escolares demonstram outras formas de comunicação estabelecidas entre si.

Este estudo se caracteriza por ser do tipo descritivo e observacional. A sua abordagem é micro-etnográfica e surge como uma alternativa importante no momento em que temos uma preocupação direcionada às manifestações corporais de um aluno com deficiência mental durante o recreio escolar.

Com base nessa perspectiva, podemos defini-lo como um estudo de caso. $O$ estudo de caso permite-nos fazer aquilo que GEERTZ (1989) definiu com sendo uma descrição densa.

Este autor explica que, na realidade cultural, se expõe a sua normalidade sem reduzir sua particularidade. Ao tentar-se entendê-la, mais lógica e singular ela nos parece. "Isso a torna acessível, pois colocá-la no quadro de sua própria banalidade dissolve sua opacidade" (GEERTZ, 1989,p.24).

Para a concretização deste estudo sobre as manifestações corporais no recreio escolar, escolhemos um aluno com deficiência mental: CARLOS $^{5}$ - 9 anos de idade, portadordaSíndromedeDown ${ }^{6}$, matriculado a três anos numa escola municipal da cidade de Porto Alegre.
Esclarecemos que não esteve em foco identificar como as habilidades motoras do aluno em estudo ocorrem. Isto, porque, a delimitação das manifestações corporais, pelas relações de poder, dão-se pelo contexto em que os escolares estão envolvidos e não pelas suas capacidades em realizar determinados movimentos. Mesmo uma criança sem a condição da deficiência mental está sujeita às relações de poder que irão influenciar as suas manifestações corporais.

A proposta de observarmos um aluno com deficiência mental no recreio escolar irá oferecer as seguintes informações: em primeiro, a descrição, importante forma de registro que destaca um saber e estabelece uma relação de poder; em segundo, aquilo que está registrado não procura localizar o poder, mas sim, identificar como ele transita no espaço e como influencia as manifestações corporais do sujeito envolvido; e, em terceiro, oferece subsídios para uma análise sobre as manifestações corporais numa perspectiva que aponta como as vontades do aluno são estimuladas, reprimidas, incitadas, anuladas, oportunizadas e disputadas.

Os procedimentos investigatórios apoiaram-se na técnica da observação passiva, sendo realizada por um único pesquisador. Dessa forma adotou-se a postura de não intervir sobre as situações que ocorriam no recreio, nem solicitar a direção da escola que modificasse a organização do recreio durante o estudo de campo. Com isso pretendia-se garantir que não houvesse uma modificação das manifestações corporais dos escolares. Foram definidas pautas de observações e identificamos as categorias de análise: Regularidade no Recreio e Agressividade no Recreio. O recreio nesta escola tinha a duração de 15 minutos. Foram feitos de dois á três registros por semana na parte da tarde. Fizemos 16 observações no recreio totalizando um tempo de $237 \mathrm{mi}-$ nutos. O corte temporal foi de abril à junho de 2000. Passamos, portanto, a tratar da apresentação e discussão das informações colhidas no estudo de campo.

\section{O (Re) conhecimento do Campo}

A escola em que Carlos estuda localiza-se na Vila São Gabriel, Bairro Camaquã de Porto Alegre. No período 
da tarde, possui 475 alunos e alunas. Conforme nos informou o secretário da escola, ela está voltada para atender as classes populares. As conversas que tivemos com os profissionais da mesma, relataram que, não havia problemas em relação as situações de violência, neste turno.

Durante as primeiras observações, percebemos que a escola não tem um projeto que organize esse momento. Identificamos que existe uma preocupação em garantir alguns adultos circulando pelo espaço. As intervenções geralmente ocorrem quando são chamados em situações específicas para resolver injustiças que possam ocorrer.

O recreio apesar de ser um momento importante para os escolares, e acontecer sem um projeto que distribua as possibilidades para a sua ocupação, deixa em aberto outras formas de relação entre os escolares. Se as manifestações corporais dos alunos e alunas são influenciados pelas relações de poder que se estabelecem, seria fundamental que os educadores fizessem intervenções para que seja possível garantir a democratização dos espaços.

Para identificarmos algumas possibilidades corporais que existem no espaço da escola, fizemos a seguinte organização: Escorregador 1 (El); Escorregador2 (E2); Trepa-trepa (TT); Prédio 1 (PI); Prédio 2 (P2); Prédio 3 (P3); Prédio 4 (P4); Pátio Central (PC); Pátio de Terra (PT);Quadra 1 (Q1);Quadra 2(Q2); Pátio da Caixa d'Água; Corredor entre o muro e o P1; Corredor do fundo do PI.

A seguir, resgatamos uma descrição sobre o recreio para apresentar um quadro de como ele é utilizado pelos escolares.

\footnotetext{
"Durante o recreio escolar, podemos observar os meninos e as meninas jogando voleibol ou futebol na quadra. A sua frente, na outra quadra, estão outros meninos jogando futsal. Ao seu lado, está o pátio de terra onde escolares de idades diferenciadas podem ser encontrados. Estão subindo e descendo os escorregadores. Utilizam o trepa-trepa, pulam corda, ficam em cima das árvores, passam correndo por ele para chegar ao pátio central da escola. É nesse último local que se concentra grande parte dos escolares. Situados entre os prédios e o portão
}

de entrada da escola, jogam futebol, ficam sentados conversando, lanchando, caminhando e pulando corda. Do seu núcleo, podemos perceber que existe uma concentração de escolares no corredor lateral. Neste local, observamos meninos jogando futebol com uma garrafa de plástico, meninas pré-adolescentes conversando seus segredos. De tempos em tempos, cruzam por este corredor, meninos e meninas que estão brincando de pegapega. Ao cruzarem pelo pátio central, eles se encaminham ao corredor; quando saem deste, têm duas opções: ou voltar para o pátio central ou cruzar pelo pátio de terra. Ao tomarem a segunda opção, passam correndo por esse espaço e, em algumas vezes, dirigem-se para o pátio da caixa d'água. Desse local, podem-se visualizar as quadras desportivas. Quando o sinal que anuncia o final do recreio toca, observamos os corpos gritando, correndo em direção ao pátio central. $\mathrm{O}$ espaço é modificado ficando somente a paisagem por onde os escolares estiveram presentes."

Esta descrição nos mostra que o recreio é um momento diretamente relacionado com práticas que envolvem o lazer de seus participantes. Permite identificar que ali existe uma geografia de corpos dispersos e em constante relação com os demais.

Todas estas manifestações corporais aproximam-se daquilo que os autores que resgatamos para refletir sobre o recreio já haviam comentado. Porém, ainda carecia um registro de um aluno com deficiência mental neste espaço.

\section{Regularidade do Comportamento Observado no Recreio}

Para comentarmos as regularidades de Carlos, destacamos que, durante o recreio, ele explora o seu corpo correndo, subindo no escorregador, no trepa-trepa, empurrando e agarrando os colegas. Entende aquilo que the é falado ou explicado. Em algumas cenas em que o observamos, percebemos que, muitas vezes, está tentando agredir uma menina em particular e, quando tem interesse em outra coisa, como subir no escorregador, alguns meninos o estimulam a sair atrás dessa menina. Muitas vezes, troca empurrões com outros colegas e/ ou observa o que está sendo feito no recreio pelos outros. Em momentos diferentes, tenta vivenciar algumas 


\begin{tabular}{|c|c|}
\hline $\begin{array}{l}\text { Comentar sobre as } \\
\text { manifestações } \\
\text { corporais no } \\
\text { recreio escolar é } \\
\text { situar essa } \\
\text { descrição num } \\
\text { saber sobre este } \\
\text { sujeito. Um saber } \\
\text { que se afasta } \\
\text { daquilo que era } \\
\text { esperado na } \\
\text { integração. }\end{array}$ & $\begin{array}{l}\text { brincadeiras ou jogos, } \\
\text { mas nem sempre é } \\
\text { incluído nelas. Interage } \\
\text { com os outros, } \\
\text { provocando situações } \\
\text { que envolvem empur- } \\
\text { rões, ameaças de } \\
\text { agressividade, gestos } \\
\text { ofensivos. } \\
\text { Pelos registros feitos } \\
\text { durante as primeiras } \\
\text { idas à escola, o nosso } \\
\text { participante sempre } \\
\text { era localizado no }\end{array}$ \\
\hline
\end{tabular}

mesmo lugar (pátio de terra). Com o decorrer das observações, começamos a localizá-lo nos demais espaços.

Pode-se dizer que, no recreio, três espaços são da sua preferência: o pátio de terra; o espaço atrás do Prédio 4; e o pátio central. Muitas vezes, ele deixa de explorar os Escorregadores 1 e 2, porque outros estão ocupando ou recebe empurrões. Quando os utiliza, está sozinho.

As manifestações corporais de CARLOS nos permitem perceber que elas são influenciadas por relações de poder. Nesse sentido a contribuição de FOUCAULT (1998) é esclarecedora, pois, ela nos fez refletir que o corpo e os gestos do aluno com deficiência mental fossem identificados, reconhecidos e constituídos a partir das ações que ele executa ou deixa de fazer. Isto, portanto, é um dos efeitos do poder.

Percebemos isso quando, no recreio, ele fica alguns momentos sozinho representando situações que observou, como, por exemplo, um arremesso de uma pedra. Quando percebe os escolares fazendo algo que lhe interessa, procura participar junto. Geralmente seaproxima daqueles que têm entre sete e oito anos de idade, pois estes permitem a sua presença. Imitando atitudes que presencia, podemos observar que, em alguns momentos, agride com pontapés meninos e meninas. Nestas situações, as falas dos escolares fazem os seguintes registros:
'"O guri, o guri é louco'. Outros falam: 'Eu vou te quebra apau'. 'Capeta', 'Ele é louco'. 'Ele está dando nas gurias'. Quando os escolares o empurram ou o machucam, ele chora, sendo depois consolado por quem está perto. As suas interações com os demais acontecem quando corre atrás de alguém, foge, empurra e é empurrado, quando acompanha os outros no que estão fazendo, enfim, quando utiliza as possibilidades corporais que este espaço lhe estimula."

Comentar sobre as manifestações corporais no recreio escolar é situar essa descrição num saber sobre este sujeito. Um saber que se afasta daquilo que era esperado na integração. Falar das interações com os demais escolares desloca-nos para a idéia de convívio social. Narrar que ele assimila informações lentamente, que interage com crianças em idade cronológica menor que a sua, ser chamado de louco, de capeta, é direcionar os nossos esforços para pensar nos saberes que se constituem sobre o deficiente mental. Isto pode ser situado naquilo que Gore (1994) trata em relação aos regimes de verdade, pois, estes registros sobre Carlos, constituem-se num lugar que o desfavorece.

Para que possamos estabelecer algumas relações sobre aquilo que Carlos faz e o que mais ocorre no recreio, apresentamos a seguir uma quantidade de manifestações corporais que os escolares exploram: jogar futebol; subir no trepa-trepa; ficar no escorregador; ficar na gangorra; balançar-se na corda; subir nas árvores; pendurar-se nas árvores; pega-pega; saltar de cima do escorregador para o chão; pular corda; observar os outros colegas; simulação de brigas; fazer acrobacias; meninos menores jogam futebol no terreno perto das árvores; as meninas sobem no trepa-trepa; algumas meninas ficam no escorregador; as meninas assistem aos meninos jogando futebol; dois grupos de meninas brincam de pular corda; jogar tazo, jogar bafo; caminhar pelos espaços; ficar sentado nos bancos do pátio central. Dentro dessa dispersão de escolares pelo espaço, diversas aprendizagens acontecem.

Considerando essa identificação do aluno Carlos, esclarecemos que ele seguidamente está observando os colegas naquilo que estão fazendo. Podemos perceber essa 
afirmação com mais clareza considerando os recortes que fizemos, conforme podemos ler a seguir:

"Está observando um grupo de meninas conversando. Quando chegou más perto, uma delas o afastou; ao perceber algumas meninas, sai correndo atrás delas. Do alto do escorregador, observa o que acontece ao seu redor; briga com uma menina (que vamos chamar aqui de Liana); contorna o P1 dirigindo-se para o pátio central; está subindo e descendo do Escorregador 2. Observa os meninos jogando futebol; sobe no trepa-trepa e fica observando dois meninos que estão no outro lado e, quando eles descem, desloca-se acompanhando-os. Corre em direção ao pátio central e, depois de ver o jogo de futebol, imita ser o goleiro, flexionando os joelhos."

Podemos perceber que as vivências de Carlos incitamno a realizar algumas manifestações corporais (correr, trepar, arremessar, etc.) da mesma forma que outras são reprimidas (não ser aceito no jogo de futebol ou subir no escorregador, etc.). As relações de poder que se estabelecem neste momento individualizam as suas ações. Em relação a estas individualidades, registramos o seguinte noutro recreio:

\footnotetext{
"Carlos está subindo no escorregador, observa os colegas. Está sozinho. A aluna Liana foi provocada por ele e saiu correndo para não ser pega. Neste momento, Carlos está no núcleo do pátio central e observa os escolares. Saiu caminhando com uma colega. Deslocaram-se para o corredor que existe entre o Prédio 1 e o muro que fica em frente à calçada. Está procurando a aluna Liana. Agora está sozinho em frente à porta do mesmo prédio $\mathrm{e}$ observa um menino no pátio central chorando. Correu em direção ao pátio de terra, ficando em frente ao trepatrepa, mas não sobe nele. Depois, desloca-se para o centro do pátio de terra. Ao ameaçar, com um galho, uma menina, esta lhe deu um tapa na mão, e sua amiga empurrou-o. Uma outra menina mexe com ele, dizendo: ' Vem', pro vocando-o a correr atrás dela. Agora a menina conversa com ele e, logo em seguida, lhe dá um beliscão no antebraço, afastando-se para se juntar às suas amigas. Ao subir no trepa-trepa, observa dois meninos no outro lado e aproxima-se deles. Quando eles descem, ele também se desloca acompanhando-os."
}

E interessante analisarmos o conteúdo das observações da seguinte forma: ao comentarmos a regularidade de Carlos tendo como relação aquilo que os escolares fazem, estamos situando uma categoria hierárquica que esta presente para

ele. Em outra pers- O recreio, desse aluno, pectiva - a suafaz-nos refletir que, integração -, o durante este cotidiano, nosso olhar registra a experimenta essas sua relação com o manifestações corporais espaço e os demais dentro de um espaço mos que, nesse onde existem outras mos que, nesse
momento escolar, possibilidades de encontra formas de vivenciá-los. convivência possíveis.

Na última observação, encontramos um exemplo muito esclarecedor para percebermos como algumas das manifestações corporais de Carlos são incitadas pelos escolares. Nesse contexto existem outras manifestações corporais que Carlos deixa de vivenciar. Muitas vezes fica jogando pedra nos escolares chamando a atenção para si, fica no muro de arrimo observando os escolares jogando futebol, fica sozinho e permanece no pátio de terra.

Sugerindo algumas saídas, identificamos no desporto uma das alternativas viáveis enquanto reconhecimento pelos outros, uma prática que deve ser estimulada e garantida pela escola nos momentos do recreio.

\footnotetext{
"Começa a correr atrás da bola. Durante este momento, não chega perto dos meninos que correm atrás da bola, ou seja, não disputa a posse da bola. Quando ela bola chegou na sua direção, ele fugiu dela, mas imitou um movimento de chute. No momento em que a bola bateu no seu corpo, um menino apontou o dedo para ele e um outro lhe deu um empurrão com o ombro".
}

Esta descrição nos mostra que ele já está desportivizando-se. Propostas que incluam o desporto no recreio podem ser percebidas no estudo de SANTOS (1998), quando apresenta uma série de manifestações corporais a serem praticadas pelos escolares sob o olhar e organização dos adultos, tendo como princípio a participação de todos os escolares.

O recreio, desse aluno, faz-nos refletir que, durante este cotidiano, experimenta essas manifestações corporais 
dentro de um espaço onde existem outras possibilidades de vivenciá-los. O que percebemos, foi que durante o recreio, CARLOS possuía uma regularidade que durante os meses de abril a junho nos mostraram que, provavelmente as situações registradas não iriam modificar-se. Certamente estas modificações poderiam acontecer se a escola organizasse de outra forma o seu recreio.

A regularidade, passa a incorporar-se como uma categoria que influencia as manifestações corporais. Esta influencia está diretamente ligada à forma como as relações de poder ocorrem. Nas descrições que apresentamos, podemos perceber que elas assumem um lugar no qual os próprios escolares estabelecem regras e territórios. Outras regularidades que se fazem presentes podem ser localizadas na categoria de agressividade.

\section{Situação de Agressividade}

Durante o período em que ficamos observando Carlos, percebemos que, quando ele está no recreio, juntamente com os escolares, experimenta situações nas quais os pontapés e empurrões são utilizados para garantir as vontades de alguns sobre os outros.

"Sozinho, sobe e desce do escorregador deslizando com os pés. Na terceira vez que tenta subir, é impedido por um colega. Quando este menino se afasta, ele volta a subir no Escorregador 2. Aparecem outras crianças, e, depois de repetir várias vezes a descida pelo escorregador com os joelhos, este grupo o afasta. Longe do E2, ele fica observando-o."

Nesse registro localizamos uma forma de coerção que limita as suas ações. Deixa de manifestar-se corporalmente porque não consegue impor a sua vontade. Ser afastado de um grupo, receber um pontapé, ser impedido de realizar algo, ser agredido, brigar com as meninas são experiências que vivência. Estas deslocam algumas possibilidades da realização de manifestações corporais, são ações sobre outras ações possíveis (Foucault, apudDeleuze, 1998).

A seguir trazemos mais um registro:
"O recreio já começou, o aluno Carlos está entre o P2 e a lateral do P4. Nesse lugar, ele ameaça com uma pedra a menina P. Na parede do P4 está sendo construído um muro de djolos para colocar as latas de lixo. Ela fala: 'Sai, sai', e ele lhe dá um pontapé nos pés. Outra menina fala: 'Deixa ele', e levou-a para o trepa-trepa. Como ele as seguiu, sobe para bater na aluna Liana e, depois, apanha terra e joga em direção a ela. Ela saiu correndo dali, e Carlos a seguiu. Ficou no centro do pátio de terra. Fica caminhando em círculos e depois observa alguns escolares no Escorregador 2. Aparece um menino que o estimula a sair arras daquela menina. Está conversando com ele, e Liana está por perto. Os dois ficam na posição de cócoras. Quando tenta levantar-se para ir atrás dela, o menino o impede. Agora está perto do muro de tijolos, está brigando novamente com aquela aluna. Logo em seguida, saiu correndo atrás dela na direção do trepatrepa. A menina jogou areia nos seus olhos, e ele ficou chorando. Outros meninos o levaram até o bebedouro para lavar o rosto. Após lavar o rosto, novamente sai atrás da mesma menina, e esta vai para o trepa-trepa. Um escolar, novamente, o impede de pegá-la."

Uma situação similar, como ser conduzido para o banheiro porque ficou chorando após ser empurrado para o chão, foi registrada em outra observação. Essas atitudes nos mostram que era um comportamento no sentido de evitar que os adultos pudessem ficar sabendo que o aluno Carlos sofreu uma agressão.

Apesar dessas situações que envolvem agressividade por parte de Carlos, não podemos dizer que ele é uma criança agressiva. Entendemos que esta é uma forma que encontrou para estabelecer relações com alguns escolares, uma estratégia para estabelecer vínculos com os outros escolares.

Noutro recreio, registramos algumas situações que mostram como a sua integração está comprometida, no momento, em que não é reconhecido na sua particularidade:

"Antes de iniciar o recreio, localizei o aluno do estudo, utilizando o Escorregador 1, que fica próximo ao prédio dos escolares da educação infantil. Ao passar para o Escorregador 2, começou a disputar espaço com uma menina mais alta do que ele, sendo, então, agredido por ela. Quando estava chorando, três meninas chegaram perto dele, um adulto que passou por perto o levou para a secretaria. Ele somente saiu quando tocou o sinal para o 
início do recreio. Pegou uma pedra que estava no chão e ficou segurando-a com uma das mãos. Observa quem ainda está no Escorregador 2 e desloca-se na direção desses alunos. Antes de chegar perto deles, a menina com quem brigou em outro recreio (Liana) está com as suas amigas e chegam perto dele para provocá-lo. Tenta sair atrás dessa menina, especificamente. As meninas chegam perto dele, corre atrás delas, contornando o Prédio 4 e parando atrás dele. Logo em seguida, elas chegam perto dele novamente. Ao pegar uma pedra, um adulto pede para largá-la. Uma menina comenta: 'Ali o Carlos vai atira a pedra na criança', outra fala para a amiga: 'Corre guria; corre, guria', segurando o Carlos. Comentando sobre o ocorrido, a aluna Liana diz o seguinte: 'O Carlos não vai me pega, ele vai me mata'. Nesse momento, no pátio de terra, um menino o está ameaçando, eles estão perto do Escorregador 1.0 menino fala com ele, provavelmente comentando sobre as meninas, e ele corre ameaçando, pois, com os dedos de uma das mãos, aponta para elas. Quando ele se levanta para ir atrás delas, este lhe segura abraçando-o pelas costas e derrubando-o no chão. Esta cena se repete por três vezes, quando o Carlos começa a chorar. Ao tentar repetir o que estava fazendo, um terceiro menino aparece para proteger Carlos. Este, após ajudar a levantá-lo, segura o braço do menino que estava agredindo o Carlos e o derruba várias vezes, até que este fica caído e chorando no chão. Toca o sinal para o final do recreio, Carlos corre em direção ao pátio central e, enquanto espera a professora, fica empurrando os colegas da turma".

Duas análises podem ser feitas a partir desse registro. A primeira localiza-se no tipo de relação que Carlos estabeleceu com a aluna Liana. Sair atrás dela, tentar agredi-la, ser provocado para pegá-la, etc, são ações que ocorreram durante as observações. Novamente observa-se que esta relação de poder influencia as suas manifestações corporais.

Se, por um lado, estabeleceu uma comunicação com os escolares por meio dessas manifestações corporais, por outro, ele é envolvido por uma forma de relação que representa a sua identidade como um sujeito que só pode interagir com os colegas com pontapés, empurrões, etc.

Numa segunda análise, destacamos o momento em que Carlos está sendo agredido, e aquele que o protege utiliza a agressão. Quando observamos a violência sendo respondida por ela mesma, identificamos uma forma de comunicação que os escolares estabelecem entre si que reforça a lei do mais forte confirmando aquilo que SANTOS (1998), MANDARINO ENETTO (1998) e GRUGEON, (1995,apud ALTMANN, 1999) já haviam percebido nos seus estudos. Parece que a única forma encontrada para se fazer justiça em relação ao agressor de Carlos seria na mesma moeda. Este é um tipo de relação que FOUCAULT (1998) não reforça, pois ela se baseia na coerção física. Este tipo de relação limita outras possibilidades a serem vividas pelo aluno com deficiência mental. $\mathrm{Na}$ perspectiva foucaultiana, VEIGA-NETO (2000), explica que existe uma diferença entre poder e violência que não é de grau, e sim quantitativa.

\footnotetext{
"Uma relação de violência age sobre o corpo, sobre as coisas. Ela força, ela submete, ela quebra, ela destrói; ela fecha todas as possibilidades; não tem, portanto, junto de si, outro pólo senão aquele da passividade e, se encontra uma violência, a única escolha é tentar reduzi-la. Uma relação de poder, ao contrário, se articula sobre dois elementos que lhe são indispensáveis por ser exatamente uma relação de poder; que o "outro" (aquele sobre o qual ela se exerce) seja inteiramente reconhecido e mantido até o fim como o sujeito da ação; e que se abra, diante da relação de poder, todo um campo de respostas, reações, efeitos, invenções possíveis."(p. 63)
}

Como se pode perceber, as situações de agressividade são negativas, pois elas fecham outras possibilidades de interação. A relação presente se situa numa microfísica na qual a coerção sobre o corpo é a sua finalidade. Uma forma de imposição pela força.

"Encontrei-o atrás do P4, observando os escolares. Um
grupo de meninos estava simulando uma briga no pátio
central, ele se aproximou e tentou brigar com um meni-
no mais alto. Logo em seguida, deu com o joelho no
traseiro de uma menina e preparou-se para a briga fa-
zendo uma pose de luta. Ela lhe deu um pontapé, e ele
revidou atirando uma pedra. Em face do quadro apresentado, concordamos com SANTOS (1998,p. 143), quando destaca que "aliberdade de movimentos de alguns oculta as relações de poder que são estabelecidas neste espaço para garantir que outras vontades sejam reprimidas". Estas, portanto, são situações que se repetem. Sendo nos pátios, nos escorregadores, etc, que as suas manifestações corpo- 
rais são envolvidas por essas relações.

Dentro da categoria da agressividade percebeu-se que durante as observações as estas situações continuaram acontecendo. Isto, permitiu refletir a partir de um recorte do seu tempo na escola e sobre o processo de integração vivenciado no recreio.

\section{Considerações Finais}

Este estudo nos permitiu refletir a respeito da integração, pois, o seu poder está em investir sobre a convivência das diferenças no espaço escolar. Nesse sentido, foi possível identificar que existem condições adversas para esta concretização. A seguir destacamos algumas considerações:

a) Percebemos que as categorias "regularidade" e "agressividade", delimitam e estimulam algumas manifestações corporais de Carlos. Com isso, outras possibilidades são impedidas. Na regularidade, foi apresentado um cotidiano no qual Carlos apresentava determinadas manifestações corporais. Pode-se perceber, também, que, em relação aquilo que os escolares faziam nos recreios, as suas possibilidades de ação eram determinadas pelas relações de poder ali estabelecidas. A agressividade nos mostrou o quanto a cultura que se constituiu no recreio escolar influencia este aluno. Por outro lado, era, também, uma forma de perceber-sejunto aos outros. Ambas, apresentaram uma realidade que ultrapassa os romantismos que a integração educacional carrega.

\begin{tabular}{|c|c|}
\hline $\begin{array}{l}\text { Temos o } \\
\text { entendimento de que } \\
\text { conseguimos avançar } \\
\text { sobre a questão da } \\
\text { integração, não para } \\
\text { nega-la, mas para } \\
\text { mostrar em que base } \\
\text { é possível discuti-la. }\end{array}$ & 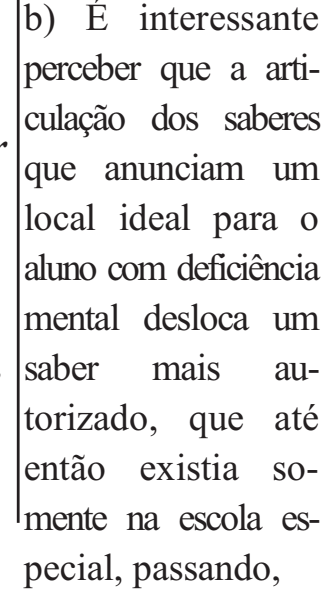 \\
\hline
\end{tabular}

também, para a escola fundamental. Com isto, apresenta-se mais um ponto de referência, com outras perspectivas para este escolar. Esta condição de possibilidade é fundamental para constituir-se outras verdades sobre a sua formação.

c) A escola, portanto, estabelece um quadro de referência para Carlos, no qual as suas práticas delineiam um campo de afirmações e negações. As afirmações de que é possível pensar outro local para a formação do aluno com deficiência mental. A negação de que as manifestações corporais constituem saberes que apresentam uma desvantagem para ele.

d) $\mathrm{O}$ estudo realizado nos acena para outras investigações, tendo como foco, tratar da percepção que os escolares tem sobre o aluno com deficiência no recreio escolar. Dessa forma, a entrevista semi-estruturada pareceria uma boa alternativa.

e) Temos o entendimento de que conseguimos avançar sobre a questão da integração, não para nega-la, mas para mostrar em que base é possível discuti-la. Nesse momento foi possível fazer um (re) conhecimento de uma realidade que está presente em diversas escolas públicas e privadas. Portanto, seria fundamental que as escolas reservassem um momento para pensar sobre a organização de projetos que distribuíssem os espaços, constituindo outras relações de poder.

Este é um caminho possível de um recreio escolar que garanta as diversas manifestações corporais de seus escolares, e, em particular, do aluno com deficiência mental, ou seja, a proposição de uma diversidade de práticas relacionadas ao lazer tendo como princípio a possibilidade parcial e provisória da integração.

\section{Referências}

1.ALMEIDA PauloA-O lazer no espaço escolar. In: $11^{\circ}$ ENAREL: lazer, meio ambiente e participação humana. Fozdo Iguaçu, 1999. p. 310-13.

2. ALTMANN, Helena. Marias (e) homens nas quadras: sobre a ocupação do espaço físico escolar. EDUCAÇÃO \& REALIDADE: das diferenças. Porto Alegre, v.24, n.2, jul/dez, 


\section{(1)}

1999.p.157-173.

3. BURBULES, Nicholas C. e RICE, Suzanne. Diálogo entre as diferenças: continuando a conversação. In: SILVA, Tomás T. (org). Teoria Educacional Crítica em TemposPós-Modernos 1.ed. Porto Alegre: Artes médicas, 1993. p. 173-204.

4. CAMARADEDEPUTADOS.Lei deDiretrises eBases da Educação. Brasília, 1996. (mimeog)

5.CHERRYHOLMES, Cleo, H. Projeto social para o currículo: perspectivas pós-estruturalistas. In: SILVA, Tomás T. (org.). Teoria Educacional Crítica em Tempos PósModernos 1 .ed. Porto Alegre: Artes médicas, 1993.p. 143172

\section{COORDENADORIANACIONALPARAINTEGR} $\mathrm{A}$

\section{ÇÃO DA PESSOAPORTADORA}

DEDEFICIÊNCIA.Declaração de salamanca e linha de ação sobre as necessidades educa

tivas especiais.Brasília: Corde, 1994.

7.CONSELHOREGIONALDESERVIÇOSOCIAL.Coletâ nea de leis revisada e ampliada. Porto Alegre: CRESS, 2000.

8. DELEUZE, Giles. Foucault. 4.ed. São Paulo: Brasiliense, 1998.

9. FARIA, Eliane L. Tempos, espaços e práticas escolares: o corpo que brinca na escola. In: $11^{\circ}$ ENAREL: lazer, meio ambiente e participação humana. Foz do Iguaçu, 1999. p.30O-6.

\section{FERNANDES, R M. NETO, C MORATO, P. Jogo e} interação social. Estudo do jogo entre crianças normais e com síndroma de down do $\mathrm{I}^{\mathrm{O}}$ ciclo do ensino regular de área de Lisboa. In: NETO, C. (Edit). Jogo \& desenvolvimento da criança. Faculdade de Motricidade Humana. Lisboa, 1997. p. 71-82

11.FOUCAULT, Michael. Microrísica do poder. 12.ed Organização e Tradução: Roberto Machado. Rio de Janeiro :EdiçõesGraal,1998.

12. GEERTZ, Cliffort. A interpretação das culturas. Rio de Janeiro: LTC - Livros Técnicos e Científicos Editora S A, 1989.

13. GORE, Jennifer M. Foucault e educação: fascinantes desafios. In: SILVA, Tomas Tadeu (org). O sujeito da educação: estudos foucaultianos. Petrópolis: Vozes, 1994, p.9-20
14. LOURO, Guacira Lopes. Gênero, sexualidade e educação: uma perspectiva pós-estruturalista. Petrópolis, RJ: Vozes, 1997.

15. MACHADO, Roberto. Ciência e saber: a trajetória da arqueologia de MichelFoucault. 2. ed. Rio de Janeiro: Graal, 1988 .

16.MANDARINO,Cládio Marques e NETTO,Francisco Camargo. Fundamentos teórico-metodológicos da educação física: uma experiência sobre o gênero na escola especial. Revista Perfil. Porto Alegre. Ano 3, v. 3, p. 17-22, 1999.

17. MANDARINO, Cláudio Marques. Relações que envolvem poder nas manifestações corporais de dois alunos com deficiência mental matriculados no ensino fundamental: estudo de casos no recreio escolar. Porto Alegre: UFRGS, 2000. (Dissertação de Mestrado)

18. MAZZOTTA, Marcos J. S. Educação Especial no Brasil: História e políticas públicas. São Paulo: Cortez, 1996.

19. NETO, Carlos. Tempo \& espaço de jogo para as crianças: rotinas e mudanças sociais. In: . (Eàit). Jogo \& desenvolvimento da criança. Faculdade de Motricidade Humana. Lisboa., 1997. p. 10-22.

20. PEREIRA B.O NETO, C SMTTH, P. Osespaços de recreio e a prevenção do "bullyng"na escola In: NETO, C. (Edit). Jogo \& desenvolvimento da criança. Faculdade de Motricidade Humana Lisboa., 1997 p. 238-257.

21. RAMALHO, Maria H. da Silva. O recreio pré-escolare a motricidade infantil na perspectiva da teoria da ecologia do desenvolvimento humano. Santa Maria: Universidade Federal de Santa Maria, 1996. (Tese de Doutorado).

22. SANTOS, Edmilson Santos. Educaçãofisica escolar: Corpo, Cultura ecurrículo. Porto Alegre: UFRGS/ESEF, 1998. Dissertação deMestrado.

23. SKLIAR, Carlos. A invenção e a exclusão da alteridade "deficiente" a partir dos significados da normalidade. Educação \& Realidade. Porto Alegre: Universidade Federal do Rio Grande do Sul, Faculdade de Educação, v.24, n.2, 1999.

24. VEIGA-NETO, Alfredo. Mchael Foucault e os estudos culturais. In: COSTA, Marrza V. Estudos culturais em educação. Porto Alegre: Ed. Universidade, 2000. p. 37-69 


\section{Notas}

* Mestre em Ciências do Movimento Humano EsEF/UFRGS. Professor da Universidade do Vale do Rio dos Sinos (UNISINOS)eUniversidadeLuteranado Brasil (ULBRA). Para contato: e-mail: cmandari@terra.com.br ${ }^{1}$ Edmilson Santos dos Santos. Projeto Seis e Meia. Secretaria Municipal de Educação e Cultura. Prefeitura Municipal de Porto Alegre. Transcrição da Palestra Currículo e Educação Física, outubro, 1997.

${ }^{2}$ A alteridade resulta de uma produção histórica e lingüística, de uma invenção que identifica outros sujeitos que nós, em aparência, não somos. A alteridade deficiente supõe uma aproximação educativa, como também sucede com as meninas e meninos de rua, os/as semterra, as negras e os negros, os/as indígenas, os homossexuais, os/as analfabetos/as, etc. (1999, p. 18)

${ }^{3} \mathrm{O}$ enunciado é uma função de existência (...). Ele não é em si mesmo uma unidade, mas uma função que cruza um domínio de estruturas e de unidades possíveis e que as faz aparecer com conteúdos concretos, no tempo e no espaço. Machado, R Ciência e Saber: a trajetória da arqueologia de Foucault. p.168.

${ }^{4}$ Essas ações são chamadas de manifestações corporais.

${ }^{5} \mathrm{O}$ nome aqui utilizado é fictício. $\mathrm{O}$ demais nomes que venha a aparecer no decorrer do texto, também, são fictícios.

${ }^{6}$ As questões de ordem patológica do caso em estudo não terão um momento específico para serem tratadas. Pretendemos descrevê-lo nas situações em que está presente no recreio.

Recebido em: 17.10 .01

Revisado em: 08.05 .02

Aceito em: 25.05.02 